
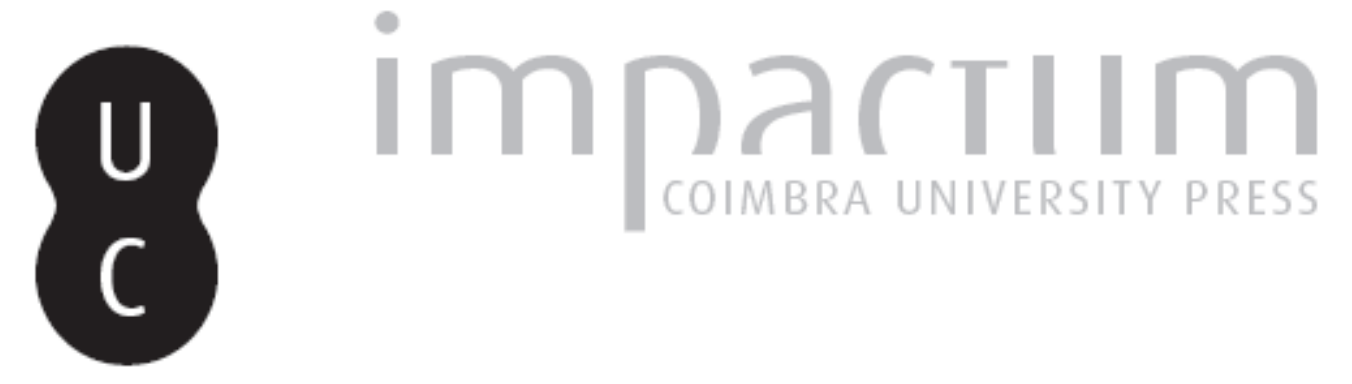

\title{
Uma breve perspetiva histórica do direito de autor
}

Autor(es): $\quad$ Dias, Maria do Carmo Branquinho Ferreira

Publicado por: Faculdade de Letras da Universidade de Coimbra

URL persistente:

URI:http://hdl.handle.net/10316.2/32306

DOI:

DOI:http://dx.doi.org/10.14195/0870-4112_10_12

Accessed : $\quad$ 26-Apr-2023 10:38:28

A navegação consulta e descarregamento dos títulos inseridos nas Bibliotecas Digitais UC Digitalis, UC Pombalina e UC Impactum, pressupõem a aceitação plena e sem reservas dos Termos e Condições de Uso destas Bibliotecas Digitais, disponíveis em https://digitalis.uc.pt/pt-pt/termos.

Conforme exposto nos referidos Termos e Condições de Uso, o descarregamento de títulos de acesso restrito requer uma licença válida de autorização devendo o utilizador aceder ao(s) documento(s) a partir de um endereço de IP da instituição detentora da supramencionada licença.

Ao utilizador é apenas permitido o descarregamento para uso pessoal, pelo que o emprego do(s) título(s) descarregado(s) para outro fim, designadamente comercial, carece de autorização do respetivo autor ou editor da obra.

Na medida em que todas as obras da UC Digitalis se encontram protegidas pelo Código do Direito de Autor e Direitos Conexos e demais legislação aplicável, toda a cópia, parcial ou total, deste documento, nos casos em que é legalmente admitida, deverá conter ou fazer-se acompanhar por este aviso.

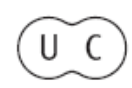



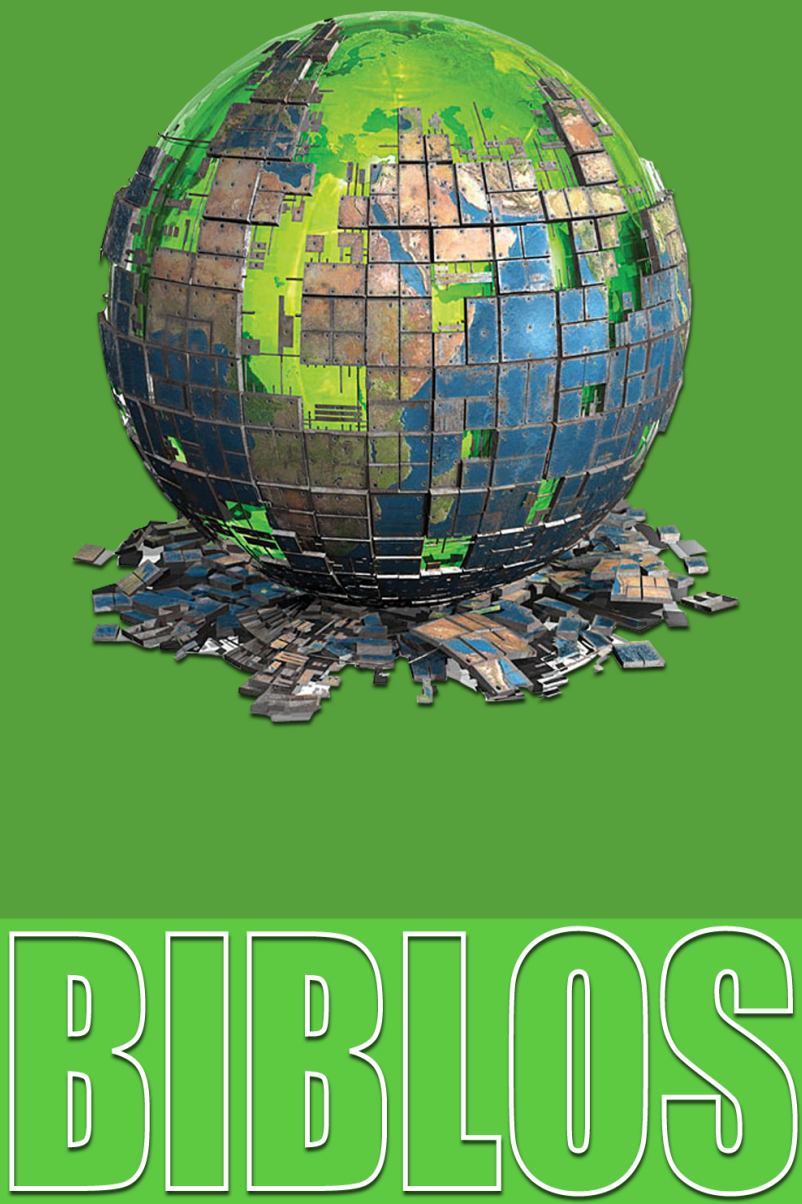

$\frac{\text { REVISTA DA FACULDADE DE LETRAS }}{\text { UNIVERSIDADE DE COIMBRA }}$ 
Biblos, n. s. X (2012) $\ldots-\ldots$

\title{
Maria do Carmo Branquinho Ferreira Dias
}

Faculdade de Letras da Universidade de Coimbra

\section{UMA BREVE PERSPETIVA HISTÓRICA DO DIREITO DE AUTOR}

\begin{abstract}
Resumo
O direito de autor é um direito humano, um direito fundamental e um direito de cultura que incide sobre as criações artísticas e literárias do ser humano, protegendo e incentivando a sua capacidade criadora. É um direito que acompanha a história da humanidade e da tecnologia. O seu reconhecimento como um elemento fundamental a nível internacional originou alterações legislativas e um esforço de harmonização das legislações dos vários países neste domínio. As caraterísticas atuais da sociedade de informação conferem novas realidades e novos desafios a este direito.
\end{abstract}

Palavras-Chave: Direito de Autor, Legislação, História do Direito de Autor.

\begin{abstract}
Copyright is a human right, a fundamental right and a right to culture that focuses on artistic and literary creations of men and women, protecting and encouraging their creative ability. It is a right that accompanies the history of humanity and technology. Its recognition as a key element in the international level led to legislative changes and an effort of harmonization of the laws of the various countries in this domain. The current characteristics of information society confer new realities and new challenges to this right.
\end{abstract}

Keywords: Copyright, Legislation, Copyright History. 


\section{Introdução}

O direito de autor remonta até à antiguidade clássica, mas é um tema que continua presente e atual nos nossos dias. Constitui um direito que surgiu com a invenção da imprensa, por Gutenberg e com a revolução industrial. A sua evolução acompanhou o desenvolvimento tecnológico e a proliferação da sociedade de informação.

$\mathrm{O}$ direito de autor consiste num direito do Homem, num direito fundamental e num direito de cultura que incide sobre as criações artísticas e literárias do homem, protegendo e incentivando a sua capacidade criadora. A proteção legal dos direitos de autor é tida como um instrumento para a liberdade de criação cultural, artística e científica (Pereira, 2008). Reúne dois requisitos especiais: por um lado a proteção das obras e, por outro, a liberdade e o incentivo à criação das obras.

$\mathrm{O}$ direito de autor incide sobre as criações originais do espírito do ser humano. É considerado um direito comum, um direito civil, um direito natural, um direito fundamental do Homem, consagrado na Declaração Universal dos Direitos do Homem e na Carta dos Direitos fundamentais da União Europeia e um direito constitucional, na medida em que se encontra patente nas constituições dos vários países.

Trata-se de um ramo do direito com autonomia e a sua importância foi reconhecida a nível internacional e, desde cedo, se procurou legislar sobre esta matéria tão importante no domínio da sociedade da informação. Nesta linha, é aprovada a Convenção de Berna, que instituiu as traves mestras do direito de autor e serviu de base para as posteriores legislações neste domínio. No âmbito internacional, convém também destacar a ação e a importância da Organização Mundial da Propriedade Inteletual (OMPI) e dos tratados celebrados no âmbito desta organização, bem como ao Acordo TRIPS, acordo esse celebrado entre a OMPI e a Organização Mundial do Comércio (OMC).

A nível comunitário, com o Tratado de Roma e o Tratado de Maastricht, encontra-se latente a referência à criação de um mercado comum e à união económica e monetária, com base numa harmonização das várias legislações. A nível nacional a legislação acompanha o desenvolvimento legislativo das instâncias internacionais e comunitárias.

As caraterísticas atuais da sociedade de informação com a crescente disseminação da informação originam novos problemas e novas formas de atuação e, consequentemente, uma nova abordagem do direito de autor. 


\section{Perspetiva histórica}

A palavra direito tem a sua origem no vocábulo latino directum, particípio do verbo dirigere, substantivado com o significado de tudo o que indica a direção das ações humanas, tudo o que é reto e justo (Gonçalves, 1961). A palavra evoluiu da forma direto para dereyto, até à grafia atual direito. Do mesmo étimo provêm, nas línguas românicas ocidentais, derecho em espanhol, diritto em italiano e droit em francês. As designações de right em inglês e Recht em alemão possuem origem germânica. Mas em latim clássico utilizava-se o termo ius ou jus, que mais tarde veio a ser adotado para expressar o mesmo conceito e que constitui o étimo de palavras portuguesas como justo, justiça, jurídico, juiz, etc.

O vocábulo direito é relativamente moderno, mas o fenómeno jurídico que ele identifica é bastante arcaico, podendo recuar ao tempo do início das relações entre os homens. Assenta na própria natureza humana, nomeadamente na sociabilidade e na faculdade de autodeterminação do ser humano. Para que a convivência e a coexistência fossem possíveis, existia uma série de regras de conduta, uma espécie de disciplina que limitava os poderes de cada um, no interesse de todos. Assim, a função do direito consistia em regular as relações dos homens entre si, de modo a permitir a coexistência e a cooperação, preservando, quer os interesses individuais, quer os coletivos. Portanto, o direito é omnipresente e historicamente permanente, mau grado a sua evolução constante (Gonçalves, 1961).

O elemento fundamental da vida social reside na existência de certa disciplina e de certas disposições. A sociedade é, pois, uma entidade cuja subsistência pressupõe a aplicação de regras que atribuem aos indivíduos funções específicas, com o objetivo de valorizar os fins sociais (Marques, 1963). A vida social surge com a vida humana, constituindo uma espécie de caraterística fundamental, atributo da vida do homem (Saraiva, 1963). Este é um ser social, que deve viver em comunidade, mas esta carateriza-se por determinadas regras que regulam a ação daquele.

O direito reveste-se de um duplo sentido: por um lado é uma faculdade ou um poder, por outro lado, é uma regra, um preceito ou conjunto de preceitos (Lima \& Varela, 1957).

Quanto à palavra autor, provém da designação latina auctore, que significa «aquele que faz crescer». $\mathrm{O}$ autor é a pessoa que fez e 
que criou uma obra. Direito de autor consistirá, pois, num direito de crescimento, na medida em que protege e incentiva a capacidade inteletual do homem, ao conceder abrigo às suas obras.

O direito de autor tem evoluído ao longo dos tempos. Podemos recuar até à Antiguidade Clássica, à Grécia e a Roma, para lhe encontrar as raízes, na medida em que se reconhecia o domínio do autor sobre as suas obras. Assim, já na Antiguidade Romana existia a Lex Fabia ex plagiariis, a que se deve a designação de plágio. Na filosofia grega podemos encontrar as raízes do direito, nomeadamente do direito de autor, em virtude de os plagiadores, pessoas que usurpavam qualquer tipo de propriedade, sofrerem condenações. Também no Digesta se encontram referências particulares ao furto dos manuscritos. Já na Idade Média se verificava a preocupação com a proteção das obras, evocando-se a lei romana para casos de proteção do direito de autor, na situação de um discípulo ter copiado as obras do seu mestre.

A perspetiva jurídica deste tema, a partir da qual se organizava, foi cedendo lugar às perspetivas económicas e tecnológicas. As grandes transformações da história começaram por ser transformações tecnológicas. A história e a evolução do direito de autor refletem o desenvolvimento da tecnologia (Stewart, 1989) e constituem um processo que reage aos desafios das novas tecnologias.

$\mathrm{O}$ verdadeiro marco da proteção do direito de autor inicia-se com a invenção da tipografia, por Gutenberg no século XV (Bertrand, 1994), e desenrola-se com a revolução industrial, nos séculos XVII e XVIII. Estes dois acontecimentos, aliados às consequências económicas, contribuíram para o desenvolvimento da humanidade e, consequentemente, introduziram modificações significativas na vida do homem, principalmente a nível inteletual. Com as novas possibilidades tecnológicas, iniciou-se o processo de impressão das obras, fruto da ação criadora do homem. Os seus pensamentos e as suas ideias tornam-se passíveis de serem divulgados amplamente à sociedade. Com a multiplicação das obras, surgiu a necessidade de estabelecer e de codificar regras a aplicar às relações entre os criadores de obras literárias e artísticas e aqueles que as difundiam e as exploravam.

Em Portugal, nos meados do século XIX, Almeida Garrett (1839) considerava o direito de autor como a mais indefesa, porém, a mais nobre e a mais inquestionável de todas as propriedades, a que se cria pela inteligência e pelo espírito do homem. 
No nosso país, tal como noutros, as primeiras medidas a favor do direito de autor diziam respeito à proteção dos impressores. $\mathrm{O}$ primeiro a obter um privilégio da impressão foi Valentim Fernandes, no ano de 1502, para a tradução do Livro de Marco Pólo. Este livro apresenta na folha de rosto: «sob o privilégio del Rey Nosso Senhor, que nenhum faça a impressão deste livro, n elo venda em todollos se 'regnos' senhorios sem licença de Valentim Fernandes sopena contenda na carta do seu privilegio» (Pereira, 2008, p. 52).

Em 1537, D. João III outorga, por meio de alvará, a Baltazar Dias um privilégio para imprimir e vender as suas obras e também um privilégio que impede outra pessoa de o fazer, salvo com sua autorização. A concessão deste privilégio é bastante importante, na medida em que se trata de um autor e não de um editor. Estes privilégios podiam ser temporários ou perpétuos e abrangiam impressores e, por vezes, autores. Aquando do término do privilégio, toda a obra impressa entrava no domínio público. Mau grado a existência destes privilégios, não havia uma lei sobre o direito de autor. A Inquisição e a Real Mesa Censória interferiam na liberdade de expressão dos criadores e tal situação contribuiu para o aparecimento de uma literatura clandestina e anónima.

No séc. XVIII, em França, os autores começaram a organizar-se, para protegerem os seus direitos enquanto criadores. Portugal não fica atrás e surgem as primeiras normas jurídicas neste domínio.

A Constituição Política da Monarquia Portuguesa, aprovada em $1822^{1}$,é a primeira lei fundamental e o primeiro documento constitucional da história de Portugal. Consagra certos direitos e deveres individuais, conferindo importância aos direitos humanos, como a garantia de liberdade, da igualdade perante a lei, da segurança e da propriedade. No título dos direitos e deveres individuais dos portugueses faz referência ao direito sagrado e inviolável da propriedade (art. ${ }^{\circ}$ 6), incidindo o seu âmbito de aplicação sobre a livre comunicação dos pensamentos, que é tida como um dos mais preciosos direitos do homem (art. ${ }^{\circ}$ ).

${ }^{1}$ Portugal (1822). Constituição Portuguesa. [Em linha]. [Consulta em 13 de setembro de 2012]. Disponível em: http://www.arqnet.pt/portal/portugal/liberalismo/const822.html 
A Carta Constitucional Portuguesa de $1826^{2}$ considera a propriedade como um direito civil e político dos cidadãos portugueses e atribui aos inventores a propriedade das suas descobertas ou das suas produções (art. $\left.{ }^{\circ} 145, \mathrm{n} .^{\circ} 21\right)$.

A Constituição Portuguesa de $1838^{3}$ influenciada pela Revolução Francesa e pelo liberalismo retomou a linha da Constituição Política da Monarquia Portuguesa de 1822. Neste texto constitucional, podemos encontrar a primeira referência sobre direito de autor ao consagrar a propriedade inteletual (art. ${ }^{\circ} 23$ n. $^{\circ} 4$ ), garantindo aos denominados inventores a propriedade das suas descobertas e aos escritores a propriedade dos seus escritos, durante o tempo que a lei proclamar.

Para este marco na nossa legislação muito contribuiu o desempenho de Almeida Garrett, como já foi referido. Em 1839, este conceituado escritor apresentou na Câmara dos Deputados um projeto de lei sobre propriedade literária e artística, o qual, mau grado ter sido aprovado em 1841, não passou de projeto, devido a questões políticas da época (Rebelo, 1999). Em 1851, o mesmo projeto volta a ser apreciado e é aprovada e publicada a lei de 18 de julho desse ano, que regula a propriedade. Surge, assim, a primeira lei portuguesa sobre o direito de autor, mantendo-se em vigor até 1867.

Nesse ano, o assunto passa a ser abrangido pelo Código Civil, elaborado pelo Visconde de Seabra. No título V, capítulo II (art. ${ }^{\circ} 570$ a art. ${ }^{\circ}$ 602) considera o trabalho literário e artístico, referindo a propriedade literária como qualquer outra propriedade móvel e com uma natureza especial. Alarga a dimensão dos autores abrangidos, incluindo os autores de qualquer obra de música, desenho, pintura, escultura ou gravura e concede aos herdeiros o direito de publicar ou de autorizar a publicação de uma obra, elevando-se o tempo de proteção de 30 para 50 anos consecutivos à morte do autor.

${ }^{2}$ Portugal (1826). Carta Constitucional. [Em linha]. [Consulta em 13 de setembro de 2012]. Disponível em: http://www.arqnet.pt/portal/portugal/liberalismo/carta826.html

${ }^{3}$ Portugal (1838). Constituição Portuguesa. [Em linha]. [Consulta em 13 de setembro de 2012]. Disponível em: http://www.arqnet.pt/portal/portugal/liberalismo/const838.html 
Em 1873, por iniciativa do escritor Costa Braga, realiza-se em Portugal uma primeira tentativa não sucedida de criação de uma sociedade com o intuito de defesa dos direitos dos autores e dos compositores teatrais.

No plano internacional, como já referimos, foi assinada a Convenção que institui a União Internacional das Nações para a Proteção das Obras Literárias e Artísticas, mais vulgarmente conhecida por Convenção de Berna. Com a Primeira República, consagra-se o direito de propriedade inteletual.Em 1918, Portugal regulamenta o registo das obras literárias, através do decreto $n .^{\circ} 4114$, de 17 de abril (regulamento do registo da propriedade literária).

Em 1925, é assinada a escritura de constituição da Sociedade de Escritores e Compositores Teatrais Portugueses, com o objetivo de proceder à união dos escritores teatrais e compositores musicais para a defesa dos seus direitos e melhoria dos seus interesses. Através do decreto n..$^{\circ} 10860$ de 1926, esta sociedade adquire personalidade jurídica, como associação legalmente constituída para a afirmação dos direitos de propriedade inteletual. Ainda no ano de 1926, é criada a Confederação Internacional de Sociedades de Autores e Compositores, a que a Sociedade de Escritores e Compositores Teatrais Portugueses adere de imediato. Esta última sociedade altera, em 1970, a sua denominação para Sociedade Portuguesa de Autores, abarcando todas as áreas da criação artística. Trata-se de uma cooperativa de responsabilidade limitada, para a gestão do direito de autor, de acordo com a legislação portuguesa e com a internacional. Em 1982, a Sociedade Portuguesa de Autores decide consagrar o dia 22 de maio como o Dia do Autor Português e, mais tarde, em 1984, é reconhecida pelo Governo Português como pessoa coletiva de utilidade pública. Em 1989 procede-se à constituição do Grupo Europeu das Sociedades de Autores e Compositores, de que a Sociedade Portuguesa de Autores é membro fundador. Pertence, também, à Confederação Internacional das Sociedades de Autores e Compositores e ao Bureau Internacional das Sociedades de Reprodução Mecânica. No $70 .^{\circ}$ aniversário da sua criação, é condecorada com a Ordem de Mérito Nacional pelo Presidente da República. A sua relevância na sociedade portuguesa é notória, tanto mais que constitui o mais antigo e representativo organismo de gestão coletiva do direito de autor. 
No ano de 1927, é publicado o decreto-lei n. ${ }^{\circ} 13725^{4}$, de 27 de maio, que estabelece o regime da propriedade literária, científica e artística. Este diploma resulta do culminar das reclamações que os escritores e artistas nacionais exerceram sobre o poder político, para a realização de uma reforma da lei reguladora dos direitos de autor, mais conhecida como lei da propriedade literária. Abarca certas disposições gerais como o direito de publicação, o direito de propriedade literária e artística e o direito de reprodução, o contrato de edição, os contratos de assinatura literária e bibliografia, certas disposições especiais sobre a propriedade artística, as transmissões, onerações e o registo, o nome literário ou artístico e os títulos das obras e, por fim, a violação e a defesa dos direitos de autor. Contém dois importantes princípios: o reconhecimento do direito de autor como perpétuo e a dependência da proteção, condicionada à publicação, representação ou exposição da obra (Portugal, 1927). Mas, com o desenvolvimento da nossa sociedade, reconhece-se que este diploma não responde às solicitações.

Nesta altura, alguns autores teatrais portugueses, de que podemos destacar Henrique Lopes de Mendonça (1856-1931), constituíram a Associação de Classe dos Autores Dramáticos Portugueses, que não vingou no tempo.

Em 1966 publica-se o Código do Direito de Autor ${ }^{5}$, que desde logo se verifica encontrar-se desfasado das novas tecnologias de produção e de difusão. O decreto-lei n. ${ }^{0} 13725$, de 27 de maio de 1927 foi revogado pelo decreto-lei n. ${ }^{\circ} 46980$, de 27 de abril de 1966. No seu texto, afirma:

Procedeu-se a uma revisão desse projeto, na medida do necessário para o atualizar e sempre com a preocupação, que também o domina, de procurar a mais equilibrada harmonização dos vários interesses em jogo neste fundamental setor da vida nacional [...]. Houve ainda a preocupação de harmonizar o texto com o projeto futuro do Código Civil (Portugal, 1966, p. 631).

${ }^{4}$ Portugal (1927). Decreto-Lei n. ${ }^{\circ} 13725$, de 27 de maio (regime da propriedade literária, científica e artística). Diário do Governo (27.05.1927).

${ }^{5}$ Portugal (1966). Código do Direito de Autor. Diário da República, I Série 99 (27.04.1966), p. 630-647. 
Este decreto estabelece o regime jurídico do direito de autor e mantém-se em vigor até 1985, ano em que se verifica a publicação de um novo decreto-lei que institucionaliza o Código do Direito de Autor e dos Direitos Conexos.

O Código Civil de $1966^{6}$ também inclui no seu texto a propriedade inteletual, considerando como objeto do direito de propriedade, as coisas corpóreas, móveis ou imóveis (art. ${ }^{\circ} 1302$ ) e que tanto os direitos de autor, como a propriedade industrial devem estar sujeitos a legislação especial (art. ${ }^{\circ}$ 1303).

A lei civil coloca a propriedade inteletual no capítulo relativo à propriedade em geral. Este facto é bastante significativo, na medida em que o direito de autor é tido como um direito de propriedade, mas que não se encontra totalmente de acordo com as prerrogativas do regime de propriedade instituído pelo Código Civil.

A Constituição Portuguesa de $1976^{7}$, diploma fundamental do nosso ordenamento jurídico, consagra novos princípios em matéria de liberdade de criação artística. Considera a propriedade como um direito fundamental (Caetano, 1981).

Art. ${ }^{\circ}$ 42..: Liberdade de criação cultural:

1 - É livre a criação inteletual, artística e científica.

2 - Esta liberdade compreende o direito à invenção, produção e divulgação

da obra científica, literária e artística, incluindo a proteção legal dos direitos de autor (Portugal, 1976).

E daqui se infere, desde logo, que o legislador constitucional quis expressar o seu reconhecimento e consequente proteção legal aos autores dos direitos que como tal foram reconhecidos, elevando-os à dignidade constitucional.

Em 1985, é publicado um novo Código do Direito de Autor e dos Direitos Conexos ${ }^{8}$, através do decreto-lei n. ${ }^{\circ}$ 63/85, de 14 de março, que é alterado pela lei . $^{\circ} 45 / 85$, de 17 de setembro; pela lei n. ${ }^{\circ} 114 / 91$,

${ }^{6}$ Portugal (1999a). Código Civil [1966]. Coimbra, Coimbra Editora

${ }^{7}$ Portugal (1998a). Constituição da República Portuguesa de 2 de Abril de 1976. Edição organizada por J. J. Gomes Canotilho \& Vital Moreira. 5. ed. Coimbra, Coimbra Editora.

${ }^{8}$ Portugal (1985a). Decreto-Lei n. ${ }^{\circ} 63 / 85$, de 14 de março, Código do Direito de Autor, Diário da República, I Série 61 (14.03.85), p. 662-689. 
de 3 de setembro; pelo decreto-lei n. $.^{\circ} 332 / 97$, de 27 de novembro e pelo decreto-lei n. ${ }^{\circ} 334 / 97$, de 27 de novembro. Novas alterações são introduzidas, nomeadamente, pela lei n. $.^{\circ} 50 / 2004$, de 24 de agosto (transposição para a ordem jurídica nacional da diretiva 2001/29/CE, do Parlamento Europeu e do Conselho, de 22 de maio de 2001, relativa à harmonização de certos aspetos do direito de autor e dos direitos conexos na sociedade da informação); pela lei n. ${ }^{\circ}$ 24/2006 (transposição para a ordem jurídica nacional da diretiva 2001/84/CE, do Parlamento Europeu e do Conselho, de 27 de setembro, relativa ao direito de sequência em benefício do autor de uma obra de arte original que seja objeto de alienações sucessivas no mercado de arte, após a sua alienação inicial pelo seu autor) e pela lei n. ${ }^{\circ} 16 / 2008$, de 1 de abril (transposição para a ordem jurídica interna da diretiva 2004/48/CE do Parlamento Europeu e do Conselho, de 29 de abril, relativa ao respeito dos direitos de propriedade inteletual).

O Código do Direito de Autor e dos Direitos Conexos incide sobre a obra protegida e o direito de autor; sobre a utilização da obra; sobre os direitos conexos e, finalmente, sobre a possível violação e defesa do direito de autor e dos direitos conexos. As linhas mestras deste novo código encontram-se de acordo com a Convenção de Berna e com as políticas comunitárias.

A nível internacional, no século XVIII, publicam-se, em Inglaterra e em França, as primeiras leis sobre o direito de autor.

Portugal (1985b). Lei n. ${ }^{\circ} 45 / 85$, de 14 de março, altera por ratificação o Decreto-Lei n. ${ }^{\circ}$ 63/85, de 14 de Março e o Código do Direito de Autor e dos Direitos Conexos, Diário da República, I Série 214 (17.09.85), p. 2970-3005.

Portugal (1991). Lei n. ${ }^{\circ} 114 / 91$, de 3 de setembro, altera o Código do Direito de Autor e dos Direitos Conexos. Diário da República, I-A Série 202 (03.09.85), p. 4634-4637.

Portugal. (1994). Lei n..$^{\circ}$ 252/94, de 20 de outubro, transposição para a ordem jurídica nacional da Diretiva 91/250/CEE, do Conselho, de 14 de Maio, relativa à proteção jurídica dos programas de computador. Diário da República I-A Série 243 (20.10.1994), p. 6374-6376.

Portugal (1997a). Decreto-Lei n. ${ }^{\circ} 332 / 97$, de 27 de novembro, altera o Código do Direito de Autor e dos Direitos Conexos, Diário da República, I-A Série 275 (27.11.1997), p. 6393-6394.

Portugal (1997b). Decreto-Lei n. ${ }^{\circ} 334 / 97$, de 27 de novembro, altera o Código do Direito de Autor e dos Direitos Conexos, Diário da República, I-A Série 275 (27.11.1997), p. 6396-6398. 
Em Inglaterra, a origem deste direito remonta aos privilégios para a imprensa, concedidos aos Stationers, que constituíam uma espécie de Liga fundada em Londres em 1403 e que compreendia livreiros e iluminadores. Em 1557, os Stationers receberam uma Carta Real, mais conhecida por Mary's Charter, que: «granted the Company a virtual monopoly over printing and bookselling both in London and throughout the kingdom» (Feather, 1994,p. 15). Mais tarde, mais concretamente em 1710, foi promulgado, também em Inglaterra, o Estatuto da Rainha Ana, que garantia aos autores dos livros um direito sobre os seus exemplares, isto é, afiançava-se a propriedade dos livros impressos. Surge, como consequência desta lei, a conceção inglesa denominada copyright, que é retomada na legislação norte-americana. Esta lei determina, ainda, a proteção através do copyright a todos os produtores de obras inteletuais, quer sejam criações do espírito, quer sejam contribuições de natureza material (Pereira, 2008). Esta conceção de copyright está intimamente associada à natureza da própria propriedade (Feather, 1994).

Nesta linha, convém fazer referência aos processos judiciais, como o Tonson v. Collins, o Donaldson v. Beckett e o Millar v. Taylor, de 1769, nos quais a jurisprudência inglesa define o copyright como um direito de propriedade e um instrumento jurídico de proteção. Atualmente encontra-se em vigor o Copyright, designs and Patents Act de 1988 que veio substituir o Copyright Act de 1956. Esta lei introduz em Inglaterra certas disposições comunitárias.

Em França, os primeiros privilégios terão sido concedidos por volta de 1507, no reinado de Luís XII. Consistiam em licenças de exploração da imprensa para determinadas obras. Após a Revolução Francesa e a consequente abolição dos privilégios, foi necessário proteger as obras e a sua reprodução. Chapelier (1791) defende a proteção da criação do espírito, afirmando: «la plus sacrée, la plus légitime, la plus inattaquable et, si je peux parler ainsi, la plus personnelle de toutes les propriétés, est l'ouvrage, fruit de la pensée d'un écrivain».

Ainda em França, em 1725, o advogado Louis d'Héricourt (1687-1752) utilizava pela primeira vez a designação de direito de autor nas alegações de um processo entre livreiros da cidade de Paris. E em 1777 o dramaturgo Pierre-Augustin de Beaumarchais (1732-1799), uma das figuras mais emblemáticas do Século das Luzes, incitava os autores de teatro a organizarem-se para defesa dos seus direitos que, muitas vezes, eram usurpados pelas pessoas que promoviam os espetáculos. 
No século XX, surgiram novas leis, como a lei de 11 de março de 1957, que é a base do direito de autor francês, a lei de 3 de julho de 1985 , a lei n. ${ }^{\circ} 92-597$ de 1 de julho de 1992, que diz respeito à propriedade inteletual e, finalmente, a lei de 1 de agosto de 2006, que transpõe a diretiva 2001/29/CE.

A evolução do direito de autor francês encontra-se associada ao relevante domínio da jurisprudência, principalmente no que concerne aos requisitos de proteção, estabelecendo o princípio de que uma obra será objeto de proteção independentemente do seu mérito ou da sua função e consagrando o princípio de que o requisito para a proteção reside na criação da obra (Pereira, 2008).

Na Alemanha, na base do Urheberrecht estiveram os privilégios de impressão (Druckprivileg). O Urheberrecht concentrava-se, no início, em redor da figura do editor, mau grado a sua evolução ter sido processada por referência ao autor, que passou a ser considerado a sua figura central, em detrimento da figura do editor (Pereira, 1998). Desenvolveu-se a proteção do autor, baseada na sua criatividade inteletual e este passou a ser uma figura muito importante no âmbito do direito de autor (Ascensão, 1998). A evolução do Urheberrecht é marcada pela passagem dos privilégios de impressão ao direito dos criadores inteletuais. Kant defendeu a fundamentação personalista do direito de autor, na medida em que se tratava de direito inato a este (Pereira, 2008).

As principais leis alemãs são duas: a lei de 1965, que consagra a teoria monista que atribui ao autor proteção para os seus interesses morais e patrimoniais e a lei de 2002, que incide sobre o direito de autor na sociedade de informação.

Na Itália, vigora o decreto legislativo n. ${ }^{\circ} 68$, de 9 de abril de 2003, que transpõe para a ordem jurídica interna italiana a diretiva 2001/29/ /CE, relativa à harmonização de certos aspetos do direito de autor e direitos conexos na sociedade de informação; na Dinamarca e na Noruega, a consagração deste direito de autor verifica-se entre 1741 e 1814 e, atualmente, ambos os países atualizaram as suas leis sobre este direito, de acordo com as principais diretivas comunitárias.

Em Espanha, as primeiras leis sobre o direito de autor surgem no século XIX, com a publicação do decreto $n .^{\circ} 265$ de 1813 , que estabelece regras para conservar aos escritores, a propriedade das suas obras; com as leis de 1823 e de 1847 sobre a propriedade das obras literárias; 
com a lei de 1879 que incide sobre a propriedade inteletual, que é reformulada em 1834. Em 1966, os direitos de propriedade inteletual nas obras cinematográficas são objeto de legislação e, nos anos de 1992, 1996, 1998 e 2006, a lei da propriedade inteletual é objeto de alterações, algumas derivadas da transposição de diretivas comunitárias sobre a matéria.

No continente americano, nomeadamente no Brasil, a primeira lei sobre direito de autor surgiu em 1827. Em 1830, o Código Criminal do Império incidiu também sobre o mesmo direito. A lei de Medeiros e de Albuquerque, em 1898, dava proteção aos direitos por um prazo de 10 anos e o registo era considerado como uma formalidade do direito de autor. Atualmente está em vigor a lei n. ${ }^{\circ} 9610$ de 19 de fevereiro de 1998, que abriga, sob a denominação de direitos autorais, este direito, bem como os direitos conexos. O prazo de proteção situa-se nos 70 anos após a morte do autor.

Nos Estados Unidos da América, a origem do direito de autor tem a marca da influência do copyright de Inglaterra. As primeiras leis denotam este cunho britânico. A primeira lei é conhecida como o primeiro Copyright Act de 1790 e consagra o copyright como direito de autor, na mesma linha da lei proclamada pela Rainha Ana de Inglaterra. Esta lei americana distingue três objetivos: a promoção do conhecimento, a preservação do domínio público e o aumento da criação e distribuição das obras, em favor do autor. Defende a proteção limitada aos direitos que eram concedidos, que o copyright não era um direito natural, protege a exploração comercial das obras e, finalmente, garante primeiro o interesse geral e só a seguir o interesse do autor. Com o Copyright Act de 1909, a novidade reside na propriedade e já não no monopólio, como referia a lei anterior. Posteriormente o US Copyright Act de 1976 introduz algumas modificações: o conceito de proteção do copyright é alterado; introduz-se o copyright eletrónico e a doutrina do fair use e a natureza do direito de autor pende para o lado dos direitos de monopólio (Pereira, 2008). Em 1998, os Tratados da OMPI são revertidos para a ordem jurídica dos Estados Unidos da América através da conhecida lei Digital Millennium Copyright Act. Estas lei foi sancionada pelo Presidente Bill Clinton em 28 de outubro de 1998 e implementa os Tratados da Organização Mundial da Propriedade Inteletual (OMPI), aprovados em 1996, adicionando a secção 1201 ao Título 17 do 
U.S. Code $e^{9}$, denominada «Circumvention of copyright protection systems». Presentemente, vigora o Copyright Law of the United States and Related Laws Contained in Title 17 of the United States Code, de 2007.

ALei Millennium Digital é bastante importante no domínio do direito de autor no mundo digital, nos Estados Unidos da América. Encontra-se associada à história deste país (Boucher, 2003). Procura responder a uma vasta gama de problemas existentes. Introduz medidas de índole tecnológica, um regime de proteção da integridade da informação e determinadas regras sobre os limites de responsabilidade por parte dos prestadores dos serviços em linha. Procurou consagrar no texto da lei o princípio do fair use como uma cláusula geral. O princípio do fair use permite que a utilização de uma obra não seja considerada objeto de violação de direito de autor (em determinados casos). Este princípio representa uma forma de defesa nos casos de violação dos direitos de autor, sendo de caráter geral e incidindo assim sobre todas as formas de utilização que não tenham sido autorizadas e sobre todo o tipo de obras (Pereira, 2008b). O princípio do fair use destaca-se também no ambiente digital, permitindo a utilização para uso privado, preservando a liberdade de expressão e a liberdade criativa.

Constitui um instrumento muito importante para certas instituições, para apoio ao ensino e à investigação, para a preservação e conservação documentais e para políticas de digitalização (Hirtle et al., 2009).

A Lei Millennium Digital apresenta dois objetivos: o primeiro reside na constatação da tecnologia digital e da lei aplicável. O segundo objetivo incide mais na determinação da necessidade da intervenção adicional, no sentido de proteger os objetivos presentes na lei de direito de autor (Hausmann, 2003).

Realça o papel desempenhado pelo direito de autor na sociedade americana, legitimado pela Constituição dos Estados Unidos da América, que considera fundamental promover o progresso da ciência e das artes, assegurando, por um determinado tempo, aos autores e aos inventores, o direito exclusivo aos seus escritos ou às suas descobertas (art. ${ }^{\circ}$ 1. $^{\circ}$, secção 8). O direito de autor é considerado como um fator de incentivo ao trabalho da criatividade do autor (Gross, 2003).

9 Vide Texto da Lei dos Estados Unidos da América: http://www.law.cornell. edu/uscode/17/ 
Esta lei apresenta-se com grande valor, pois aborda os direitos de autor que constituem um tema atual e de grande importância na sociedade. Afeta concomitantemente as indústrias culturais, nomeadamente as empresas que controlam a produção e a distribuição, por exemplo de textos, de sons ou de imagens. O cidadão comum apresenta um grau de preocupação que deve ser considerado relevante em relação às novas tecnologias e à democracia cultural, numa sociedade cada vez mais globalizada. Abrange, por um lado, os direitos de autor sobre a propriedade inteletual e, por outro, os dos editores. A sociedade necessita desta dicotomia e entre eles devia existir uma forma de equilibrar os interesses de cada um.

A Lei Millennium Digital introduz certos itens de caráter tecnológico (Pereira, 1999) e apresenta, ao mesmo tempo, um regime de proteção para os direitos de autor. Contempla também exceções, procurando garantir os direitos de autor e instituiu um novo direito, o denominado direito de acesso (Pereira, 2002b), interligado com a proteção técnica das obras, podendo ser necessária alguma decifração, utilização de palavra-chave ou algum tipo de remuneração para aceder à obra.

Procura a regulação do comércio eletrónico das obras intelectuais protegidas pelo direito de autor e enuncia medidas contra o incumprimento das normas estipuladas neste direito e estabelece algumas exceções. Aborda o direito de autor no mundo do digital, conferindo-lhe um novo âmbito de aplicação, atribuindo-lhe atualidade. O copyright foi adaptado às novas tecnologias de reprodução e aos novos meios de distribuição como a indústria da música e da rádio e, não esquecendo o mundo das imagens, a fotografia, o cinema e a televisão (Poster, 2006).

Realça também o papel de determinadas instituições sem fins lucrativos no acesso à informação, estabelecendo um equilíbrio entre os interesses do púbico que pretende ter acesso à informação e os interesses dos detentores dos direitos de autor (Bartow, 2001).

A Lei Millennium Digital introduziu algumas alterações à legislação sobre direitos de autor na sociedade norte-americana (Clark, 2003). Reflete um considerável esforço inteletual para proteger esses direitos de forma coerente e fazer cumprir esta valência nos domínios da internet. $\mathrm{E}$, finalmente, não podemos esquecer o equilíbrio de interesses entre os direitos e os interesses deste domínio tão importante da sociedade (Hausmann, 2003). 
A nível internacional, no século XIX, em 1886 é aprovada a Convenção de Berna ${ }^{10}$, referente à proteção das obras literárias e artísticas. Esta Convenção foi revista em Paris (1896), em Berlim (1908), em Berna (1914), em Roma (1928), em Bruxelas (1948), em Estocolmo (1967) e outra vez em Paris (1971). Foi, ainda, alvo de retificação anos mais tarde (OMPI, 1979). Portugal aderiu em 1978, por força do decreto n. ${ }^{\circ} 73 / 78$, de 26 de julho. Apresenta como missão a proteção, de uma forma eficaz e uniforme, dos direitos de autor das obras literárias e artísticas. Constituiu uma baliza importante, instrumento que funciona como um padrão do direito de autor a nível internacional (Ascensão, 2008).

No século XX e após a Segunda Guerra Mundial, a revolução legislativa acompanha o avanço das novas tecnologias. A massificação da cultura, a industrialização dos bens culturais e o mercado de dimensão mundial introduzem novos condicionalismos económicos.

Em 1948 é adotada pela Organização das Nações Unidas a Declaração Universal dos Direitos do Homem ${ }^{11}$, que consiste no mais importante instrumento internacional dos direitos do homem (Müller, 2005), que consagra o direito de autor como um direito do homem.

Art. $^{\circ} 27 .^{\circ}$

1 - Toda a pessoa tem o direito de tomar parte livremente na vida cultural da comunidade, de fruir as artes e de participar no progresso científico e nos benefícios que deste resultam.

2 - Todos têm direito à proteção dos interesses morais e materiais ligados a qualquer produção científica, literária ou artística da sua autoria (ONU, 1948).

Em 1952, é assinada por vários estados a Convenção Universal sobre Direito de Autor ${ }^{12}$, que foi revista em Paris a 24 de julho de 1971 e aprovada em Portugal em 1979, pelo decreto n. ${ }^{\circ} 140-\mathrm{A} / 79$, de 26 de

${ }^{10}$ OMPI (1979). Convenção de Berna: relativa à proteção das obras literárias e artísticas. [Em linha]. [Consulta em 13 de setembro de 2012]. Disponível em: http://www.wipo.int/treaties/fr/ip/berne/trtdocs_wo001.html

${ }^{11}$ ONU (1948). Déclaration Universelle des Droits de l'Homme. [Em linha]. [Consulta em 13 de setembro de 2012]. Disponível em: http://www.un.org/french/ aboutun/dudh.htm

${ }^{12}$ OMPI (1971). Convenção Universal sobre Direito de Autor. [Em linha]. [Consulta em 13 de setembro de 2012]. Disponível em: http://www.unesco.pt/ pdfs/cultura/docs/8_Convencao_direitos_autor.doc 
dezembro. Os estados contratantes, com o desejo de assegurarem a proteção dos direitos de autor sobre as obras literárias, científicas e artísticas, contribuem para o respeito dos direitos da pessoa humana e para o desenvolvimento das letras, das ciências e das artes, persuadidos de que este regime universal de proteção do direito de autor permitirá a difusão das obras e uma melhor compreensão internacional. Todos os estados se comprometem a tomar as medidas necessárias de modo a assegurarem a proteção dos direitos dos autores e de outros titulares destes direitos sobre as obras literárias, científicas e artísticas, fazendo alusão aos escritos, às obras musicais, dramáticas e cinematográficas e às obras de pintura, gravura e escultura. Esta convenção foi justificada pela necessidade de uma convenção verdadeiramente universal, ao contrário da Convenção de Berna, que tinha um cariz mais europeu; pela tentativa de superar os obstáculos resultantes de sistemas legislativos muito diferentes, por exemplo entre os vários países europeus e a América; para tentar que os Estados Unidos da América integrassem o movimento protecionista do direito de autor e para dar relevo à UNESCO, dada a querela com a OMPI (Ascensão, 2008).

Com a Convenção de Roma de $1962^{13}$ (Convenção Internacional sobre a proteção dos artistas, intérpretes ou executantes, dos produtores de fonogramas e dos organismos de radiodifusão), uma nova categoria de beneficiários é contemplada.

Ainda no circuito das legislações internacionais, convém fazer referência à Organização Mundial da Propriedade Inteletual (OMPI). Trata-se de uma instituição especializada, criada em 1967 no seio das Nações Unidas, cuja missão consiste na elaboração de um sistema internacional equilibrado e acessível, referente à propriedade inteletual, valorizando a criatividade e o estímulo à inovação, contribuindo, deste modo, para o desenvolvimento económico e para a preservação do interesse geral. O seu objetivo reside na promoção da proteção da propriedade inteletual, mediante a cooperação entre os estados e a colaboração com outras organizações internacionais. Assim, esta orga-

${ }^{13}$ OMPI (1961). Convention de Rome: Convention internationale sur la protection des artistes interprètes ou exécutants, des producteurs de phonogrammes et des organismes de radiodiffusion. [Em linha]. [Consulta em 13 de setembro de 2012]. Disponível em: http://www.wipo.int/treaties/fr/ip/rome/trtdocs_wo024. html. 
nização internacional tem o intuito de promover medidas tendentes a melhorar a proteção da propriedade inteletual em todo o planeta e harmonizar as legislações nacionais neste domínio. Trata-se de uma organização intergovernamental, composta por 183 países, responsável pela proteção da referida propriedade e pela administração de vários tratados multilaterais que versam sobre a mesma. Define propriedade inteletual como a soma dos direitos relativos às obras literárias, artísticas e científicas, às interpretações dos artistas intérpretes ou executantes, aos fonogramas e às emissões de radiodifusão, às invenções em todos os domínios da atividade humana, às descobertas científicas, aos desenhos e modelos industriais, às marcas industriais, comerciais e de serviço, bem como às firmas comerciais, etc. Abarca todos os direitos inerentes à atividade inteletual, científica, literária e artística.

Convém fazer referência aos tratados da Organização Mundial da Propriedade Inteletual (OMPI), nomeadamente ao Acordo entre a Organização Mundial da Propriedade Inteletual e a Organização Mundial do Comércio (Acordo TRIPS) ${ }^{14}$ que incide sobre os aspetos dos direitos de propriedade inteletual relacionados com o comércio. No Acordo TRIPS está presente a intenção de reduzir as distorções e os entraves ao comércio internacional e a necessidade de promover uma proteção eficaz dos direitos de propriedade inteletual, que não podem, contudo, ser obstáculos ao referido comércio internacional (OMC, 1995).

O Tratado da Organização Mundial da Propriedade Inteletual (OMPI) sobre Direito de Autor ${ }^{15}$ acrescenta aos direitos exclusivos consagrados na Convenção de Berna um direito de distribuição, um direito de aluguer e um direito de comunicação ao público e alude a uma diversificação do local e do momento, ou seja, ao acesso em linha. Abarca os princípios gerais da Convenção de Berna e apresenta como objetivos: a proteção dos direitos dos autores sobre as suas obras literárias e artísticas; a institucionalização de novas regras internacionais

${ }^{14} \mathrm{OMC}$ (1995). Accord entre l'Organisation de la Propriété Intellectuelle et l'Organisation Mondiale du Commerce. [Em linha]. [Consulta em 13 de setembro de 2012]. Disponível em: http://www.wto.org/french/docs_f/legal_f/27-trips.pdf

${ }^{15}$ OMPI (1996a). - Traité de L'OMPI sur le Droit d'Auteur. [Em linha]. [Consulta em 13 de setembro de 2012]. Disponível em: http://www.wipo.int/ treaties/fr/ip/wct/trtdocs_wo033.html 
e a precisão da interpretação de certas disposições, devido à evolução nos domínios económico, social, cultural e técnico; a evolução e a convergência das técnicas de informação e de comunicação; a proteção das obras, como um meio de incentivo à criação literária e artística e, por fim, a necessidade de estabelecer e de manter um equilíbrio entre os direitos de autor e o interesse público.

Finalmente, o Tratado da Organização Mundial da Propriedade Inteletual sobre Interpretações ou Execuções e Fonogramas ${ }^{16}$ define vários conceitos importantes, como o conceito de artista, intérprete ou executante, de fonograma, de produtor, de publicação, de radiodifusão e outros, faz alusão aos beneficiários da proteção e ainda aos direitos morais e aos direitos patrimoniais, consagra um direito de reprodução, um direito de distribuição e um direito de aluguer. Procura assegurar a proteção dos direitos dos artistas intérpretes ou executantes e dos produtores de fonogramas, estabelecendo novas regras internacionais para incidir sobre as questões motivadas pela evolução nos domínios económico, social, cultural e técnico e procurando estabelecer um equilíbrio entre os direitos dos artistas intérpretes ou executantes e dos produtores de fonogramas e o interesse público geral.

Estes acordos e tratados demonstram bem a ligação do direito de autor com o universo do comércio, com a atividade económica e com o desenvolvimento em geral.

Ao nível da Europa, com a instituição da Comunidade Económica Europeia (CEE) pelo Tratado de Roma, que entrou em vigor em 1958, com o intuito de estabelecer os fundamentos de uma união cada vez mais estreita entre os povos europeus; de assegurar o progresso económico e social, eliminando as barreiras; de melhorar as condições de vida e de trabalho; de garantir a estabilidade na expansão económica; de minimizar as desigualdades entre as várias regiões; de suprimir progressivamente as restrições ao comércio internacional e de promover a paz e as relações com os países ultramarinos, está bem patente a missão de criar um mercado comum e uma união económica e monetária e também a aplicação de políticas ou de ações comuns que encaminhem à livre circulação de pessoas, capitais, serviços e

${ }^{16}$ OMPI (1996b). Traité de L'OMPI sur les Interprétations et Éxecutions et les Phonogrammes. [Em linha]. [Consulta em 13 de setembro de 2012]. Disponível em: http://www.wipo.int/treaties/fr/ip/wppt/ 
mercadorias, à livre prestação de serviços, à liberdade de concorrência, à igualdade ou não discriminação e à solidariedade. A Comunidade Europeia procura, a todo o transe, promover o desenvolvimento das atividades económicas, o crescimento sustentável e não inflacionista, o elevado grau de convergência dos comportamentos das economias, o alto nível de emprego e de proteção social, o aumento do nível e da qualidade de vida, a coesão económica e social e a solidariedade entre os estados membros. Um dos seus objetivos consiste na tentativa de harmonização das legislações dos diversos estados membros, de modo a permitir um correto funcionamento do mercado interno, respeitando o princípio da subsidiariedade, razão pela qual os laços entre os estados e os povos europeus devem ser cada vez mais próximos, para garantir o progresso económico e social e um mercado interno sem fronteiras.

O Tratado de Roma ${ }^{17}$ não apresenta, no seu texto, qualquer alusão aos direitos de autor. Mas a jurisprudência do Tribunal de Justiça das Comunidades Europeias procedeu ao enquadramento destes e dos direitos conexos, a nível daquele tratado, de modo a garantir o bom funcionamento do mercado interno da Comunidade (Pereira, 2008). Os direitos de autor foram incorporados, pela jurisprudência comunitária, nos artigos $30 .^{\circ}$ (proibição das restrições quantitativas à importação) e $36^{\circ}$ (proteção do património nacional de valor artístico, histórico ou arqueológico e proteção da propriedade industrial e comercial) que diziam respeito à livre circulação de mercadorias. Foram, deste modo, inseridos no âmbito da propriedade comercial. Na ausência de legislação comunitária, o assunto estava sob a alçada do direito nacional de cada estado, mas o benefício era comum aos nacionais dos restantes estados membros. Contudo, estes direitos podiam ser limitados, através do princípio do esgotamento dos direitos de autor (Pereira, 2008).

A necessidade de harmonizar os direitos de autor é notória para a Comissão Europeia, que, no seu Livro Branco sobre o mercado interno, realça a importância deste domínio para a concretização do mercado interno (Comissão Europeia, 1985).

Com o Tratado de Maastricht, de 1992, que institui a União Europeia, assinala-se uma nova fase no processo de criação de uma união cada vez mais estreita entre os povos da Europa, em que as decisões serão

${ }^{17}$ União Europeia (2003). Código da União Europeia. Edit. Tizzano, António; Vilaça, José Luís da; Henriques, Miguel Gorjão. 3 ed. Coimbra, Livraria Almedina. 
tomadas a um nível muito próximo dos cidadãos. A União funda-se na Comunidade Europeia, completada pelas políticas e formas de cooperação e tendo por missão organizar de forma coerente e solidária as relações entre os estados membros e entre os respetivos povos. Os seus objetivos concretizam-se no reforço da legitimidade democrática das instituições; no melhoramento da sua eficácia; na implementação de uma união económica e monetária; na promoção do progresso económico e social, no contexto da concretização do mercado interno e do reforço da coesão; no desenvolvimento da vertente social da Comunidade e na instituição de uma política externa e de segurança comum; na livre circulação de pessoas e, finalmente, na integração europeia. O Tratado de Maastricht sofreu algumas alterações pelo Tratado de Amesterdão de 1997 e pelo Tratado de Nice. Em 2004, foi assinado o Tratado que estabelece uma Constituição para a Europa. Neste, respeita-se a riqueza da diversidade cultural e linguística da União e vela-se pela salvaguarda e pelo desenvolvimento do património cultural dos povos europeus.

Em 2007, é assinado pelos Chefes de Estado e de Governo dos 27 estados membros o Tratado de Lisboa ${ }^{18}$. Completará o processo iniciado pelo Tratado de Amesterdão e pelo Tratado de Nice, no sentido de reforçar a eficiência e a legitimidade democrática da União e a coerência da sua ação, procurando respostas mais efetivas aos desafios da nossa sociedade, reforçando a democracia na União Europeia e melhorando a capacidade de defesa dos interesses dos cidadãos.

A nível da União Europeia, com os vários tratados, institui-se uma ordem jurídica própria, integrada no sistema jurídico com primazia sobre as ordens nacionais. Esta ordem jurídica comunitária caracteriza-se por ser, essencialmente, uma fonte criadora de direito (Louis, 1986). O esforço de harmonização das legislações sobre direitos de autor torna-se uma questão premente relevando, cada vez mais, o instituto daqueles direitos. Nesta linha, foram publicadas algumas diretivas, que foram transpostas para o sistema jurídico de cada estado membro. Num conjunto de várias diretivas sobre o assunto, podemos destacar

${ }^{18}$ União Europeia (2007). Tratado de Lisboa que altera o Tratado da União Europeia e o Tratado que institui a Comunidade Europeia, assinado em Lisboa em 13 de dezembro de 2007. Jornal Oficial das Comunidades Europeias. [Em linha]. Série C, n. ${ }^{\circ} 306$ (2007). [Consulta em 13 de setembro de 2012]. Disponível em: http://eur-lex.europa.eu/JOHtml.do?uri=OJ:C:2007:306:SOM:PT:HTML 
duas muito importantes: a diretiva 92/100/CEE que abrange o direito de aluguer, o direito de comodato e certos direitos conexos aos direitos de autor em matéria de propriedade inteletual (Comunidade Europeia, 1992) e a diretiva 2001/29/CE relativa à harmonização de certos aspetos do direito de autor e dos direitos conexos na sociedade da informação (União Europeia, 2001).

No domínio do acervo comunitário dos direitos de autor, reflete-se na possibilidade de elaborar um Código Europeu da propriedade inteletual, de modo a eliminar as barreiras que dificultam o livre comércio no mercado interno da União Europeia e a harmonizar as várias legislações sobre esta matéria. A diretiva 2001/29/CE e as suas consequências a nível legislativo nos estados membros podem ser consideradas como um embrião para um futuro Código Europeu dos direitos de autor (Pereira, 2008).

No processo de harmonização das legislações dos estados membros, a União Europeia considerou a temática dos direitos de autor como um instrumento político necessário e importante para o futuro da construção da sociedade da informação (Pereira, 2002a).

Os objetivos da União prendem-se com a promoção do progresso económico e social equilibrado e sustentável, com a criação de um espaço interno sem fronteiras, o reforço da coesão económica e social e o estabelecimento da união económica e monetária. As políticas comuns são reforçadas, bem como a defesa dos direitos e dos interesses dos nacionais dos estados membros, com o estabelecimento da cidadania da união, de acordo com o princípio da subsidiariedade. A harmonização das políticas e das legislações contribuirá para a prossecução do mercado interno e para as liberdades fundamentais. Nesta linha, desenvolveram-se diretivas comunitárias para colmatar as diferenças existentes. A nível do âmbito do direito de autor, algumas diretivas estabeleceram regras, de acordo com os tratados internacionais, para regular a matéria.

Mas o direito de autor, tal como os outros direitos, não se carateriza por ser um direito absoluto (Dias, 2011). Assim, nas várias legislações, quer internacionais, quer comunitárias, quer, ainda, nos vários países, as normas sobre o direito de autor apresentam algumas disposições de exceção, nomeadamente certas instituições, como as bibliotecas, que dispõem o legado coletivo da memória cultural e científico, promovendo a leitura e fomentando a cultura. Estas exceções constituem autênticos privilégios para as bibliotecas, procurando estabelecer um 
equilíbrio de interesses dos criadores e detentores dos direitos de autor e o público em geral, sempre com o intuito de facilitar o acesso e a livre circulação da informação.

Convém, ainda destacar, no seio da União Europeia, a Carta dos Direitos Fundamentais da União Europeia, assinada em 2000 que reúne num único documento os direitos civis, políticos, económicos e sociais. Procura reforçar a proteção dos direitos fundamentais, de acordo com a evolução da sociedade, o progresso social e a evolução científica e tecnológica. Este documento trata de questões como a dignidade, as liberdades, a igualdade, a solidariedade, a cidadania e a justiça. Incide sobre a liberdade de expressão e de informação, conferindo o direito à liberdade de expressão (União Europeia, 2000).

O desenvolvimento da nossa sociedade e a proliferação de novas tecnologias de informação tornam constante esta necessidade de legislação e uma nova adequação do direito de autor face à nova realidade da sociedade da informação. Este direito acompanha o desenvolvimento desta sociedade, detendo cada vez mais uma componente económica. $\mathrm{O}$ autor como pessoa física deixa de ser o centro deste direito, partilhando-o com as empresas que atuam no mercado da sociedade de informação. Este facto origina certos problemas, nomeadamente na aplicação do referido direito. Estamos, pois, perante uma realidade que se carateriza pela multiplicação das comunicações entre as pessoas e pela difusão da informação, através de suportes digitais.

Estas novas tecnologias permitem que os utilizadores acedam à informação em qualquer momento e em qualquer lugar. Inicialmente, com a informação veiculada tradicionalmente, detinham um papel passivo no acesso e na utilização da informação. Com o desenvolvimento tecnológico e com a internet, passaram a desempenhar um papel ativo. Estamos perante uma situação nova de interatividade entre o utilizador e as obras multimédia.

No mundo digital, com cada vez mais programas de computador, bases de dados e criações multimédia, será ainda pertinente falar em direito de autor? Em nosso modesto parecer, justifica-se continuar a falar em direito de autor. Sendo um direito fundamental e um direito do homem, acompanhou desde sempre o desenvolvimento tecnológico. Se a sua criação foi produto da invenção da imprensa e da revolução industrial, é facto notório que detém uma profunda relação com a tecnologia e, certamente, não irá estagnar com a introdução das novas 
tecnologias digitais. A solução será acompanhar o desenvolvimento destas e adaptar-se às caraterísticas da sociedade atual. Tal como refere Rebelo (2002,p. 199), pode-se mesmo falar numa «reconcetualização do direito de autor», transpondo para o mundo do digital e da interatividade os preceitos existentes, moldando-os de acordo com a nova realidade, constituindo, na mesma, os pilares da sociedade de informação.

Até ao momento, estas reformas legais centram-se em beneficiar os titulares dos direitos, olvidando os interesses dos utilizadores, o que pressupõe uma clara rutura do necessário equilíbrio entre ambos os sectores. A legislação deve procurar conferir proteção aos criadores das obras para fomentar a continuação da atividade criadora, mas, também, deve facilitar o acesso às obras, para benefício da sociedade no seu conjunto.

Para conseguir o equilíbrio entre ambos os objetivos, as leis de direito de autor contam com as exceções aos direitos, isto é, nos casos em que as obras podem ser utilizadas sem autorização do titular dos direitos, quer seja de forma gratuita ou através de algum sistema de pagamento. Entre estas exceções existem umas que tiveram a sua origem, para favorecer diretamente as bibliotecas e instituições similares (arquivos, museus, etc.), para que possam cumprir a sua missão de caráter social e de interesse público. Infelizmente, a sua regulação tornou-se obsoleta e resulta inapropriada para enfrentar os problemas próprios da informação digital e das redes.

\section{Conclusão}

As raízes do direito de autor remontam à Antiguidade Clássica. Mas a sua verdadeira origem verifica-se com a descoberta da tipografia por Gutenberg. A invenção da imprensa e a revolução industrial originaram profundas alterações na vida do homem. Com a primeira, ocorre uma multiplicação de obras impressas e, como consequência, surge a necessidade de se estabelecerem leis para regularem este domínio. Deste modo, no século XVIII publicam-se as primeiras leis sobre direito de autor, no século XIX, destaca-se a Convenção de Berna e no século XX realça-se a ação da Organização Mundial da Propriedade Intelectual (OMPI) com os seus tratados e a atuação da União Europeia na harmonização desta temática. 
Como vimos, da parte das instâncias internacionais e comunitárias existiu o reconhecimento da importância do direito de autor. Mas este, tal como todos os outros direitos, não é um direito absoluto. E, assim sendo, apresenta os seus limites, que constituem restrições aos direitos exclusivos e apresentam como objetivo o estabelecimento de um equilíbrio entre as partes interessadas.

Até ao séc. XIX, o direito de autor constituía um domínio reservado às criações do homem. A partir de então alagou as suas fronteiras e acompanhou o crescimento tecnológico, defendendo sempre as ações inteletuais do homem. O progresso dos meios de reprodução e os novos meios técnicos de comunicação e difusão conferiram a este direito uma nova realidade. Com efeito, «à situação artesanal do autor que isoladamente cria e individualmente autoriza esta ou aquela utilização, sucede a cultura das massas» (Ascensão, 2008, p. 15). Com o desenvolvimento da sociedade de informação onde luzem novas tecnologias, outros problemas se colocam no âmbito do direito de autor. A sua relação com o mundo económico é cada vez mais evidente e os objetivos empresariais mais nítidos.

\section{Referências bibliográficas}

ASCENSÃO, J. de Oliveira (1998). Direitos de autor, conexos, inerentes à colocação de mensagens em rede informática à disposição do público. Revista da Ordem dos Advogados. Lisboa. Ano 58, p. 1063.

- (2008). Direito civil: direito de autor e direitos conexos. Reimpressão. Coimbra, Coimbra Editora.

BARTOW, Ann (2001). Libraries in a digital and aggressively copyrighted world. [Em linha]. [Consulta em 13 de setembro de 2012]. Disponível em: http://moritzlaw.osu.edu/lawjournal/issues/ volume62/number2/bartow.pdf.

BERTRAND, André (1994). Las obras informáticas en el derecho de autor. In: Num Novo Mundo do Direito de Autor? Tomo I. Lisboa, Edições Cosmos, p. 315-328.

BOUCHER, Rick (2003). The future of intellectual property in the information age. In: Copy fights: the future of intellectual property in the information age. Washington, D.C., Cato, p. 95-105.

CAETANO, Marcelo (1981). Constituições portuguesas. Lisboa, Verbo. 
CLARK, Drew (2003). How copyright became controversial. In: Copy fights: the future of intellectual property in the information age. Washington, D.C., Cato, p. 147-161.

COMISSÃO Europeia (1985). COM (85) 310 - L'achèvement du marché intérieur. [Em linha]. Consulta em 13 de setembro de 2012]. Disponível em: http://europa.eu/documents/comm/white_papers/ pdf/com1985_0310_f_fr.pdf

COMUNIDADE EUROPEIA (1992). Diretiva 92/100/CEE do Conselho, de 19 de novembro, relativa ao direito de aluguer, ao direito de comodato e a certos direitos conexos aos direitos de autor em matéria de propriedade inteletual. Jornal Oficial das Comunidades Europeias. [Em linha]. Série L, n. ${ }^{\circ} 346$ (1992),p.61-66. [Consulta em 13 de setembro de 2012]. Disponível em: http://eur-lex.europa.eu/ LexUriServ/LexUriServ.do?uri=CELEX:31992L0100:PT:HTML

DIAS, Maria do Carmo Ferreira (2011) Las bibliotecas públicas y universitarias ante el derecho de autor: el caso de Portugal. Granada.

FEATHER, John (1994). Publishing, piracy and politics: an historical study of copyright in Britain. London, Mansell.

GONÇALVES, Luís da Cunha (1961). Tratado de direito civil: em comentário ao Código Civil Português. Vol. 1. Coimbra, Coimbra Editora.

GROSS, Robin D. (2003). Copyright zealotry in a digital world: can freedom of speech survive? In: Copy fights: the future of intellectual property in the information age. Washington, D.C., Cato, p. 189-195.

HAUSMANN, Frank G. (2003). Protecting intellectual property in the digital age. In: Copy fights: the future of intellectual property in the information age. Washington, D.C., Cato, p. 205-221.

HIRTLE, Peter B. \& HUDSON, Emily \& KENYON, Andrew T. (2009). Copyright and cultural institutions: guidelines for digitization for U.S. Libraries, Archives, and Museums. [Em linha]. Ithaca, New York, Cornell University Library. [Consulta em 13 de setembro de 2012]. Disponível em: http://papers.ssrn.com/sol3/papers. cfm?abstract_id=1495365

LIMA, Pires de \& VARELA, Antunes (1957). Noções fundamentais de direito civil. Vol. 1. 4. . ed. Coimbra, Coimbra Editora.

- (1972). Código Civil anotado. Vol. 3. Coimbra, Coimbra Editora.

LOUIS,Jean-Victor (1986).Aordem jurídica comunitária.3 . ${ }^{\mathrm{a}}$ ed.Luxemburgo, Serviço de Publicações Oficiais das Comunidades Europeias. 
MARQUES, J. Dias (1963). Introdução ao estudo do direito. Vol. 1. Lisboa.

MÜLLER, Eugélio Luís (2005). Direito de autor: um direito humano? Estudos Jurídicos. Vol. 38, nº 1, p. 8-13.

PEREIRA, Alexandre Dias (1998). Copyright e droit d'auteur. Boletim da Faculdade de Direito da Universidade de Coimbra. Coimbra, Coimbra Editora. Vol. 74, p. 801-830.

- (1999). Comércio electrónico na sociedade da informação: da segurança técnica à confiança jurídica. Coimbra, Almedina.

- (2002a). Arte, tecnologia e propriedade inteletual. Revista da Ordem dos Advogados. Ano 62, p. 467-485.

- (2002b). Propriedade intelectual, concorrência desleal e sua tutela (penal) em Portugal. Revista da Associação Brasileira da Propriedade Industrial. Rio de Janeiro. N. . 56, p. 15-34.

- (2008). Direitos de autor e liberdade de informação. Coimbra, Almedina.

PORTUGAL (1966). Código do Direito de Autor. Diário da República, I Série 99 (27.04.1966), p. 630-647.

POSTER, Mark (2006). Information please: culture and politics in the age of digital machines. Durham \& London, Duke University Press. REBELO, Luís Francisco (1999). Garrett, Herculano e a propriedade literária. Lisboa, D. Quixote.

- (2001). O direito de autor no ciberespaço. Vida Judiciária. N. ${ }^{\circ} 43$, p. 17-22.

- (2002). Informação sobre direitos. In: Direito da Sociedade de Informação. Vol. 3. Coimbra, Coimbra Editora, p. 193-210. ISBN 972-32-1106-8.

Saraiva, José H. (1963). Lições de introdução ao direito. Lisboa.

Stewart,Stephen M.\& Sandison,Hamish(1989).International copyright law and neighbourings rights. 2. ed. London, Butterworths.

União Europeia (2001). Diretiva 2001/29/CE, do Parlamento Europeu e do Conselho, de 22 de maio de 2001, relativa à harmonização de certos aspetos do direito de autor e dos direitos conexos na sociedade da informação. Jornal Oficial das Comunidades Europeias. [Em linha]. Série L, n. ${ }^{\circ} 167$ (2001), p. 10-19. [Consulta em 13 de setembro de 2012]. Disponível em: http://eur-lex.europa. eu/LexUriServ/LexUriServ.do?uri=OJ:L:2001:167:0010:0019: PT:PDF. 